\title{
Effect of CDH1 gene methylation on transforming growth factor $\beta$-induced epithelial-mesenchymal transition in alveolar epithelial cell line A549
}

\author{
Y.Y. Liu', J.Y. Han' ${ }^{2}$, S.C. Lin ${ }^{1}$, Z.Y. Liu' ${ }^{1}$ and W.T. Jiang ${ }^{1}$ \\ ${ }^{1}$ Thoracic Surgery, the Second Affiliated Hospital of Fujian Medical University, \\ Quanzhou, Fujian Province, China \\ ${ }^{2}$ Han Junyong, Fujian Academy of Medical Sciences, Fuzhou, \\ Fujian Province, China \\ Corresponding author: Y.Y. Liu \\ E-mail: yyjycn@126.com
}

Genet. Mol. Res. 13 (4): 8568-8576 (2014)

Received July 25, 2013

Accepted December 18, 2013

Published February 13, 2014

DOI http://dx.doi.org/10.4238/2014.February.13.13

\begin{abstract}
The aim of this study was to investigate the specific molecular mechanism of the transforming growth factor $\beta$ (TGF- $\beta$ )induced epithelial-mesenchymal transition in a lung cancer cell line, and to provide new ideas for targeting therapy of lung cancer. A549 cells were treated with different concentrations of TGF- $\beta$ and 5-aza-deoxycytidine (5-aza-dC). The morphological changes after the intervention were observed. The change in the expression of the epithelial marker E-cadherin (E-cad) was detected by Western blot. The proliferation of A549 cells was measured using the MTT assay. Cell movement and invasion capacity was evaluated with the cell scratch test and invasion test. TGF- $\beta$ induced A549 cells to transform to a mesenchymal cell morphology and downregulated the expression of E-cad, and 5-aza$\mathrm{dC}$ inhibited this phenomenon. Compared with the control group, the number of transmembrane cells was higher and cell migration was
\end{abstract}


markedly increased in the experimental group with continued culture in the presence of $10 \mathrm{ng} / \mathrm{mL}$ TGF- $\beta$, showing significant differences $(\mathrm{P}<$ 0.05). CDH1 gene methylation is involved in TGF- $\beta$-induced epithelialmesenchymal transition in the alveolar epithelial cell line A549.

Key words: Methylation; Transforming growth factor $\beta$; Lung epithelial cells; Epithelial-mesenchymal transition

\section{INTRODUCTION}

Lung cancer is one of the major leading causes of death. Molecular-targeted therapy is increasingly used in the treatment of lung cancer, but its therapeutic effect is not ideal. In recent years, studies have suggest that epigenetic changes (promoter hypermethylation) are important in the inactivation of tumor suppressor genes, of which DNA methylation plays an important role in lung cancer development (Ren and Huo, 2010). In non-small cell lung cancer (NSCLC), CDH1 methylation has been shown to be associated with tumor recurrence and metastasis (Matsuzaki et al., 2005).

Promoter methylation-induced epithelial-mesenchymal transition (EMT) is an important reason for the absence of E-cadherin (E-cad) expression. In tumor progression, loss of E-cad expression can induce epithelial cells to transform into mesenchymal cells and acquire the abilities for local invasion and distant metastasis (Potocnik et al., 2001; Matsuzaki et al., 2005; Wang et al., 2006). The mechanism for the absence of E-cad expression in the EMT process is still controversial (Wheeler et al., 2001; Huang et al., 2007; Ren and Huo, 2010). In NSCLC, the frequency of CDH1 gene methylation is more than in normal lung tissue. CDH1 promoter methylation is an independent prognostic factor for NSCLC patients (Vaissière et al., 2009). Therefore, this study aimed to apply methylation-specific PCR technology to detect CDH1 promoter methylation before and after EMT in a cell model of lung cancer and Western blot analysis to detect differences in protein expression and to explore the role of CDH1 gene methylation in the loss of E-cad expression and the specific molecular mechanisms of transforming growth factor $\beta$ (TGF- $\beta$ )-induced EMT in lung cancer cells, to provide new ideas for targeted therapy of lung cancer.

\section{MATERIAL AND METHODS}

\section{Materials}

DNA modification kit was purchased from the United States of America Chemicon Company. The MSP primers were synthesized by Dingguo Biotechnology Co. (China). Taq enzymes were purchased from Dingguo. A 100-bp marker was purchased from Huamei Biotechnology Company. Power Pae3000 electrophoresis instrument and GelDoc1000 UV image analysis system and supporting analysis software were provided by Bio-Rad Company (USA). A 5417R high-speed refrigerated centrifuge, 5415C high-speed centrifuges, and nucleic acid protein measuring instrument were all purchased from Eppendorf (Germany). A series of specification pipettes were from Eppendorf. Liquid nitrogen cans, electric heated water temperature box, rabbit anti-human $\beta$-catenin, and E-cad were purchased from Dingguo. 


\section{Methods}

\section{A549 cell culture and passage}

A549 cultured cells could be passaged for 48-72 h, and after 2-4 generations, wellgrown cells were placed for overnight in serum-free low-sugar 1640 medium to obtain cells at the same level of growth and then added with different concentrations of TGF- $\beta$ for $48 \mathrm{~h}$. The morphological changes during the lung EMT were observed with a light microscope and photographed.

\section{Detection of E-cad gene promoter methylation}

The specific steps of tissue DNA extraction and methylation (bisulfite modification) were carried out in accordance with the kit instructions. The last DNA template obtained was diluted and analyzed with a UV spectrophotometer to measure $A_{260 \mathrm{~nm}}$ and $A_{280 \mathrm{~nm}}$ for evaluating DNA content and purity. DNA from every sample, 5-12 $\mu \mathrm{g}$, was taken and methylation modification was determined following the manufacturer instructions.

Methylation-specific PCR: PCR amplification primers were synthesized by Shanghai Shenggon. Methylation-specific primers: E2cadherin2M, and the sequence of the upstream primer MF: 5'-TTAGGTTAGAGGGTTATCGCGT-3', downstream primer MR: 5'-TAACTAAAAATTCACCTACCGAC-3'. The length of the amplified fragment was $116 \mathrm{bp}$. Unmethylated-specific primers: E2cadherin2U, upstream primer UF: 5'-TAATTTTAGGT2TA GAGGGTTATTGT-3', downstream primer UR: 5'-CA2CAACCAATCAACAACACA-3'. The length of the amplified fragment was $97 \mathrm{bp}$. The amplification was carried out with a hot start PCR instrument. Only the cells with fully positive amplification of methylation specific primers MR/MF were totally methylated $(++)$; the cells with positive amplification of methylation-specific primers $\mathrm{MR} / \mathrm{MF}$ and positive amplification of unmethylated-specific primers UR/UF were not completely methylated $(+)$, which were all defined as positive methylation; the cells with positive amplification of unmethylated-specific primers UR/UF and negative amplification of methylation-specific primers MR/MF were negative (-).

\section{Western blot analysis}

According to the protein quantitative results, $30 \mu \mathrm{g}$ of each protein sample was subjected to sodium dodecyl sulfate polyacrylamide gel electrophoresis (SDS-PAGE). PVDF membrane was prepared with $1 \mathrm{X}$ electrophoresis buffer, and membrane transfer was carried out at a $110-\mathrm{V}$ constant voltage on ice for $3 \mathrm{~h}$. Pre-stained molecular weight protein markers were used as standards for SDS-PAGE and Western blot. The non-specific binding sites were then removed. The target protein in the membrane was sequentially reacted with the first antibody and second antibody. The first antibody was rabbit anti-E-cad at 1:1000 dilution; the second antibody was HRP-labeled goat anti-rabbit IgG at 1:2000 dilution. The PVDF membrane was transferred to a fresh film and the developer and fixer were added for development.

\section{MTT assay}

The cells in the logarithmic growth phase were dislodged with trypsin solution and 
suspended in complete culture medium. The cells were then centrifuged, resuspended in complete medium and placed in a $37^{\circ} \mathrm{C}$ incubator with $95 \%$ humidity and $5 \% \mathrm{CO}_{2}$. After cells were completely adherent, the groups were established as follows: blank control group without TGF- $\beta 1$; experimental groups with TGF- $\beta 1$ at final concentrations of $1,2,5,10,20$ and $50 \mathrm{ng} /$ $\mathrm{mL}$; six wells were used for each group, with incubation for $24 \mathrm{~h}$. Using an enzyme immunoassay analyzer, the optical density for each well was determined at a wavelength of $490 \mathrm{~nm}$. The above test was repeated three times, and each average optical density value represented the cell proliferation capacity.

\section{Cell scratch test}

A549 cells in the logarithmic growth phase were grown at $37^{\circ} \mathrm{C}$ and $95 \%$ humidity in a $5 \% \mathrm{CO}_{2}$ incubator to form a monolayer of cells. The cell monolayer was scratched across the center of the plate bottom downwards with $200-\mu \mathrm{L}$ sterile pipette tip. The initial scratch area was observed under the microscope, and at the same time, the experimental group was treated with $10 \mathrm{ng} / \mathrm{mL}$ TGF- $\beta 1$. The degree of healing after scratches was observed and monolayers photographed every $24 \mathrm{~h}$ using an inverted microscope.

\section{Transwell invasion trial}

A549 cells in logarithmic growth phase were collected and transferred to a 24-well Transwell chamber $(8 \mu \mathrm{m})$ for the invasion assay. The experimental group was treated with $10 \mathrm{ng} /$ $\mathrm{mL}$ TGF- $\beta 1$ and the control group received an equal amount of PBS as chemotactic agent. The number of transmembrane cells was determined, and ten adjacent fields under high magnification (200X) for each membrane were counted, statistically analyzed and averaged. The number of cells showing invasion through the artificial basement membrane represented cell invasion ability.

\section{Statistical analysis}

SPSS17.0 statistical software was used for analysis. The measurement data were analyzed by a $t$-test and are reported as means $\pm \mathrm{SD} . \mathrm{P}<0.05$ represented a statistically significant difference.

\section{RESULTS}

After stimulation with TGF- $\beta$, A549 cell morphology underwent a significant change as seen under a phase contrast microscope (Figure 1). A549 cells usually have cobblestonelike epithelial morphology and growth patterns. After stimulation with TGF- $\beta$, the cell morphology was spindle-shaped. With the increase in TGF- $\beta$ concentration, this change became apparent, and cell morphology showed obvious changes. The connections between the cells became loose.

Electrophoresis results: $5 \mu \mathrm{L}$ amplification products was separated by $2 \%$ agarose gel electrophoresis, observed and photographed under UV light. Each specimen was repeatedly detected 3-4 times and considered positive when appearing positive more than 2 times. The PCR-confirmed results determined the methylation of the gene (Figure 2). A549 cells were 
positive for methylation (M1-UI) after stimulation with $10 \mathrm{ng} / \mathrm{mL}$ TGF- $\beta$, while unmethylated (M3-U3), after induction with the methylation inhibitor 5-aza-deoxycytidine (5-aza-dC; 15 $\mu \mathrm{M}$ for $72 \mathrm{~h}$ ) (Figure 2).
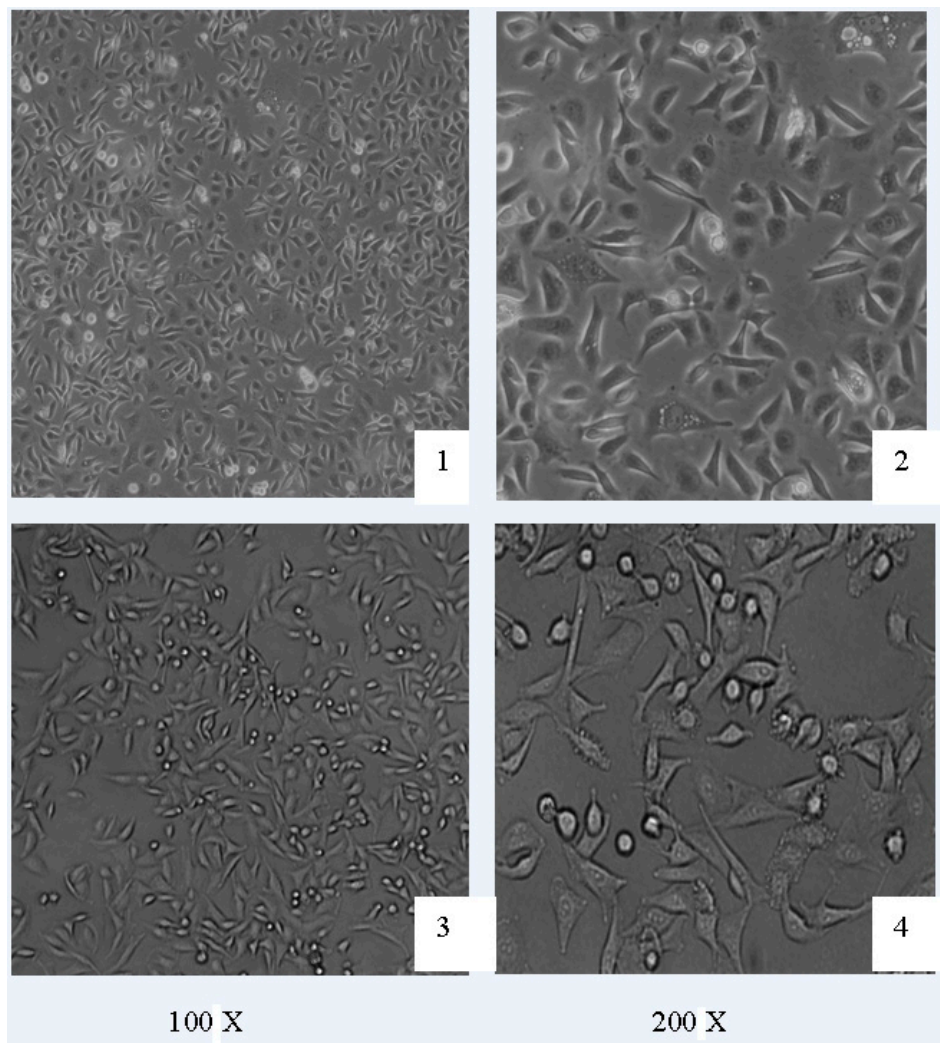

Figure 1. A549 cell morphology after the stimulation of TGF- $\beta$ under the phase contrast microscope. 1. 2. Before stimulation; 3. 4. after stimulation.

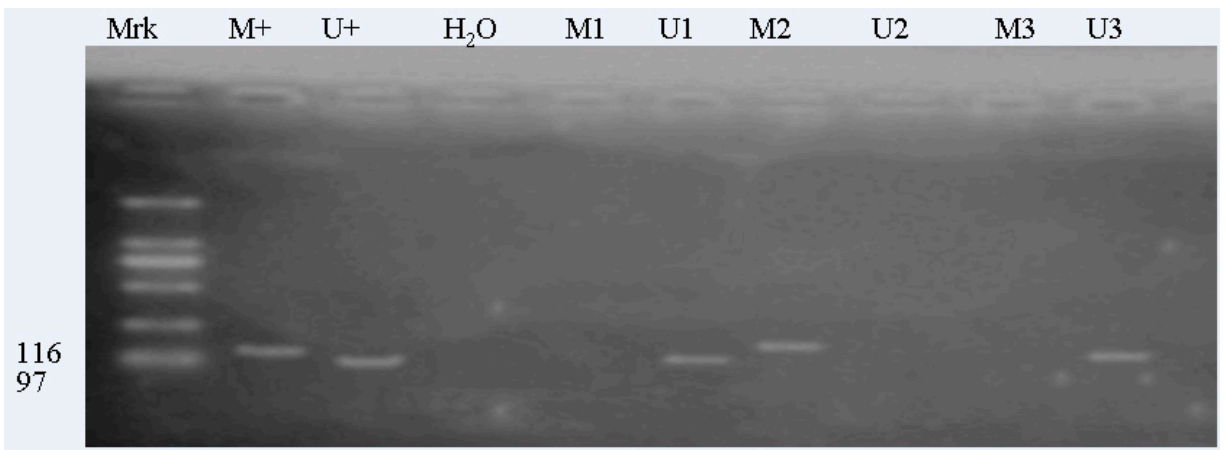

Figure 2. Methylation electrophoresis. $\mathrm{M}+=$ methylated positive control; $\mathrm{U}+=$ unmethylated positive control; $\mathrm{H}_{2} \mathrm{O}$ $=$ negative control; M1-UI $=$ before TGF- $\beta$ stimulation; $\mathrm{M} 2-\mathrm{U} 2=\mathrm{TGF}-\beta$ stimulus; $\mathrm{M} 3=\mathrm{U} 3$ inhibitor. 


\section{Analysis of E-cad expression by Western blot}

A549 cells were stimulated with $10 \mathrm{ng} / \mathrm{mL}$ TGF- $\beta$ for $48 \mathrm{~h}$, and E-cad was then determined by Western blot with an antibody. The results showed that the increase in epithelial cell marker E-cad protein weakened (compared with the control group; $\mathrm{P}<0.01$ ). After induction with the methylation inhibitor 5-aza-dC $(15 \mu \mathrm{M})$ for $48 \mathrm{~h}$, the expression of epithelial cell marker E-cad increased $(\mathrm{P}<0.01)$. These results showed that TGF- $\beta$ could decrease the expression of Ecad protein, and the methylation inhibitor 5 -aza-dC could reverse the effect of TGF- $\beta$ (Figure 3 ).

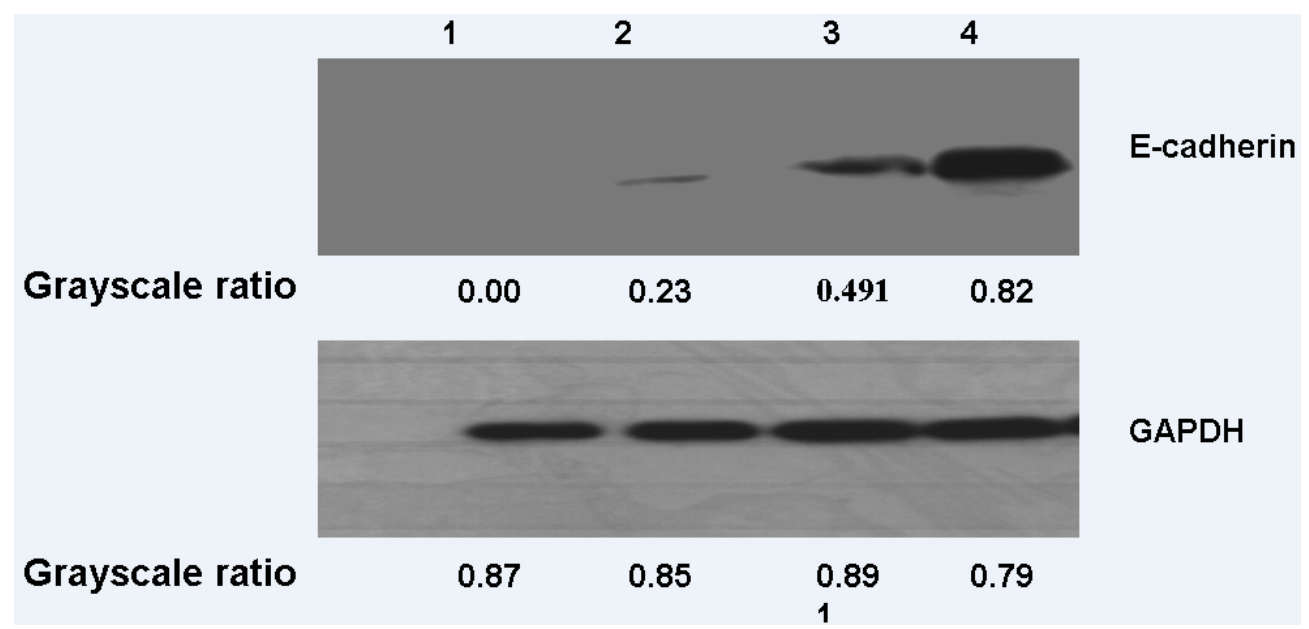

Figure 3. Western blot results. Lane $1=$ control group; lane $2=$ TGF- $\beta$ group; lane $3=$ normal group; lane $4=$ 5-aza-dC group.

\section{Effect of TGF- $\beta$ on A549 cell proliferation}

A low concentration $(1,2,5,10 \mathrm{ng} / \mathrm{mL})$ of TGF- $\beta$ promoted cell proliferation, but cell proliferation did not show a linear relationship with TGF- $\beta$ concentration. As the concentration was increased, increase in cell proliferation was not obvious (Table 1).

Table 1. The effect of TGF- $\beta$ on A549 cell proliferation.

\begin{tabular}{ccccccc}
\hline \multicolumn{7}{c}{ TGF- $\beta 1$} \\
A549 & $1 \mathrm{ng} / \mathrm{mL}$ & $2 \mathrm{ng} / \mathrm{mL}$ & $5 \mathrm{ng} / \mathrm{mL}$ & $10 \mathrm{ng} / \mathrm{mL}$ & $20 \mathrm{ng} / \mathrm{mL}$ & $50 \mathrm{ng} / \mathrm{mL}$ \\
\hline & $0 . .405 \pm 0.027$ & $0.418 \pm 0.015$ & $0.476 \pm 0.017$ & $0.537 \pm 0.042$ & $0.551 \pm 0.039$ & $0.579 \pm 0.019$ \\
\hline
\end{tabular}

Data are reported as means \pm SD.

\section{Change in cell migration ability}

After scratches, compared with the control group, cell migration was significantly enhanced and scratches healed more quickly in the experimental group, to which $10 \mathrm{ng} / \mathrm{mL}$ TGF- $\beta 1$ was added (Figure 4 ). 


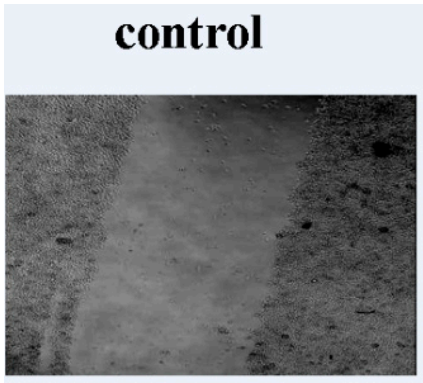

\section{+TGF- $\beta$}

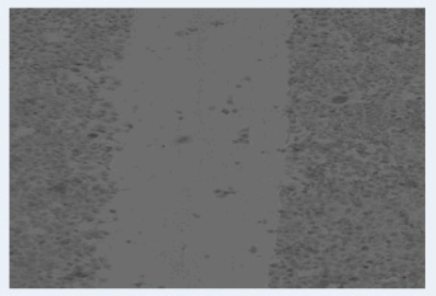

$\mathbf{0 ~ h}$
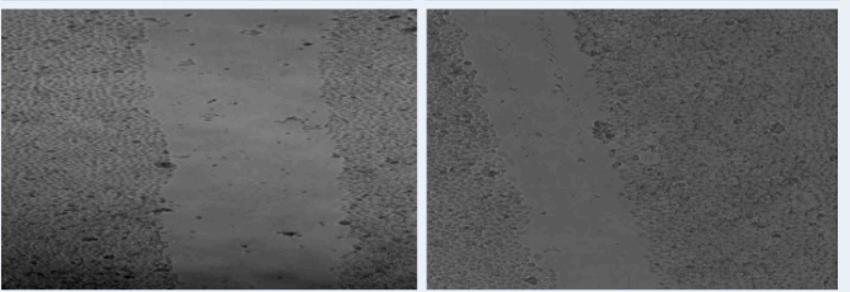

$24 \mathrm{~h}$
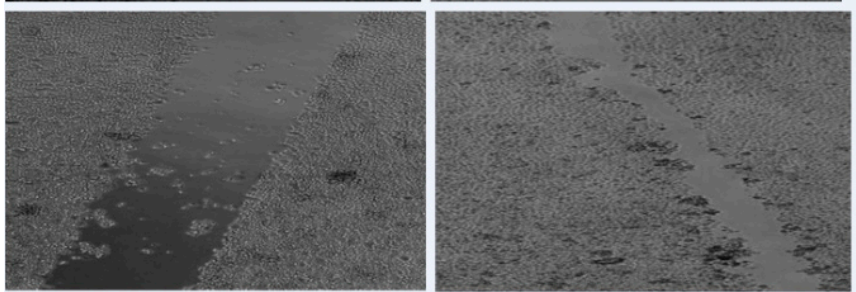

$48 \mathrm{~h}$

Figure 4. Change of the cell migration ability.

\section{Transwell invasion test in vitro}

The cells in the small Transwell chamber were cultured for $24 \mathrm{~h}$. The number of penetrating A549 cells in the control group was $58.33 \pm 5.859$. The number of penetrating cells in the experimental group with TGF- $\beta$ was significantly increased and was as high as $105.67 \pm$ 4.041. The difference was statistically significant $(\mathrm{P}<0.05)$ (Figure 5 and Table 2$)$.

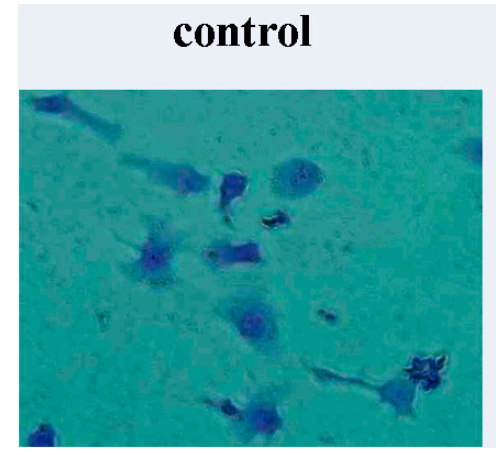

$$
+ \text { TGF- } \beta
$$

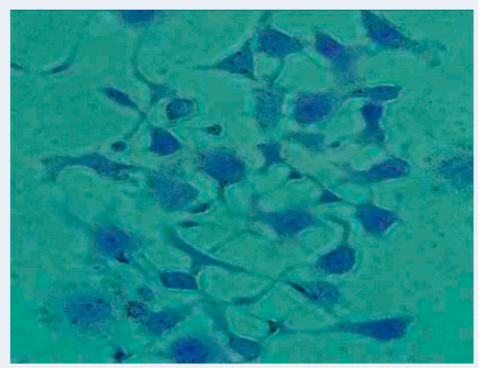

Figure 5. Transwell invasion test in vitro. 
Table 2. Effect of TGF- $\beta$ on the number of membrane traversed A549 cells.

\begin{tabular}{lccc}
\hline & Control & TGF- $\beta$ & P value \\
\hline Number of membrane traversed A549 cells & $58.33 \pm 5.859$ & $105.67 \pm 4.041$ & $<0.05$ \\
\hline
\end{tabular}

Data are reported as means $\pm \mathrm{SD}$.

\section{DISCUSSION}

Invasion and metastasis are important biological characteristics of lung cancer, and also account for treatment clinical failure (Toyota et al., 1999; Satoh et al., 2002; Kang et al., 2003; Feinberg, 2004; Chen et al., 2005). Tumor cells detached from the primary site is an initiating link to tumor metastasis. This process is closely related with reduced cell adhesion and function. A family of calcium-dependent adhesion molecules are important cell adhesion molecules, of which the epithelial calcium-dependent adhesion molecule E-cad is an important molecule in maintaining adhesion between normal epithelial cells. The E-cad protein is encoded by the $\mathrm{CDH} 1$ gene as a calcium-dependent adhesion molecule. Recent studies have shown that E-cad expression is closely related to a variety of tumor differentiation and invasion capacities (Toyota et al., 1999; Topaloglu et al., 2004; Chen et al., 2005). The reduced expression of E-cad contributes to tumor cell growth, invasion, shedding and transfer from the original tumor, where it is also a suppression factor of a variety of forms of tumor invasion and metastasis. Study of the change in E-cad molecule expression in lung cancer tissue and the mechanism involved may have a certain value for understanding the transfer mechanism and guiding clinical treatment of lung cancer.

Methylation may play an important role in the occurrence and development of cancer, especially that the promoter methylation of tumor suppressor factor is one of the main reasons for blocking gene transcription and even entire gene inactivation (Jemal et al., 2002). The upstream promoter region of the $\mathrm{CDH} 1$ gene is rich in $\mathrm{CpG}$ sequences, also known as $\mathrm{CpG}$ islands, where cytosine is usually not methylated. Gene expression is inhibited if this region is methylated after some stimulus (Choi et al., 2003; Liu et al., 2005). It is also thought that this is a tumor metastasis-related gene. The abnormal expression of E-cad may be involved in some mechanisms. CDH1 change is an important reason. $\mathrm{CDH} 1$ mutations are rare in decreased E-cad expression-related cancer. Toyooka et al. (2001) reported that CDH1 methylation may be the most important reason for the gene change (see also, Bremnes et al., 2002; Eckhardt et al., 2006; Vaissière et al., 2009).

This study was designed to apply popular methylation-specific PCR to detect the methylation degree of the $\mathrm{CDH} 1$ promoter region, Western blot to detect expression change of the epithelial marker E-cad, MTT to detect the effect of TGF- $\beta$ on A549 cell proliferation, and cell scratch experiments to detect the invasion ability of cells. Our results showed that A549 cells could be transformed to show a mesenchymal cell morphology with TGF- $\beta$ induction. 5-aza-dC can inhibit the TGF- $\beta$-induced decreased expression of A549 epithelial cell marker E-cad. In the experimental group with $10 \mathrm{ng} / \mathrm{mL}$ TGF- $\beta$, cell migration was significantly enhanced and scratches healed more quickly. The number of penetrating A549 cells in the control group was $58.33 \pm 5.859$, while in the experimental group it was $105.67 \pm 4.041$ and the difference was statistically significant $(\mathrm{P}<0.05)$. Our results further suggested that the methylation of $\mathrm{CpG}$ islands in the $\mathrm{CDH} 1$ gene promoter may directly downregulate the expression of E-cad protein, which plays an important role in the incidence, invasion and metastasis of lung cancer. 
However, not all organizations with low expression have methylation, and not all methylated organizations render low protein expression. The results suggest that there are other factors that could affect the expression of cadherin molecules. It is unclear whether $\mathrm{CDH} 1$ gene mutation and other molecular changes occur in lung tissue. Therefore, in-depth study of the molecular variation of the tumor suppressor gene $\mathrm{CDH} 1$ is of great significance for epithelial lung cancer research and the prevention and treatment of diseases.

\section{REFERENCES}

Bremnes RM, Veve R, Gabrielson E, Hirsch FR, et al. (2002). High-throughput tissue microarray analysis used to evaluate biology and prognostic significance of the E-cadherin pathway in non-small-cell lung cancer. J. Clin. Oncol. 20: 2417-2428.

Chen XF, Zhang HT, Qi QY, Sun MM, et al. (2005). Expression of E-cadherin and nm23 is associated with the clinicopathological factors of human non-small cell lung cancer in China. Lung Cancer 48: 69-76.

Choi YS, Shim YM, Kim SH, Son DS, et al. (2003). Prognostic significance of E-cadherin and beta-catenin in resected stage I non-small cell lung cancer. Eur. J. Cardiothorac. Surg. 24: 441-449.

Eckhardt F, Lewin J, Cortese R, Rakyan VK, et al. (2006). DNA methylation profiling of human chromosomes 6, 20 and 22. Nat. Genet. 38: 1378-1385.

Feinberg AP (2004). The epigenetics of cancer etiology. Semin. Cancer Biol. 14: 427-432.

Huang J, Sengupta R, Espejo AB, Lee MG, et al. (2007). p53 is regulated by the lysine demethylase LSD1. Nature 449: 105-108.

Liu YC, Shen CY, Wu HS, Chan DC, et al. (2005). Helicobacter pylori infection in relation to E-cadherin gene promoter polymorphism and hypermethylation in sporadic gastric carcinomas. World J. Gastroenterol. 33: 5174-5179.

Jemal A, Thomas A, Murray T and Thun M (2002). Cancer statistics, 2002. CA Cancer J. Clin. 52: 23-47.

Kang GH, Lee S, Kim JS and Jung HY (2003). Profile of aberrant CpG island methylation along multistep gastric carcinogenesis. Lab. Invest. 83: 519-526.

Matsuzaki K, Deng G, Tanaka H, Kakar S, et al. (2005). The relationship between global methylation level, loss of heterozygosity, and microsatellite instability in sporadic colorectal cancer. Clin. Cancer Res. 11: 8564-8569.

Potocnik U, Glavac D, Golouh R and Ravnik-Glavac M (2001). Causes of microsatellite instability in colorectal tumors: implications for hereditary non-polyposis colorectal cancer screening. Cancer Genet. Cytogenet. 126: 85-96.

Ren JZ and Huo JR (2010). Effect of 5-Aza-CdR on expression and methylation of E-cadherin gene in human colon carcinoma cells. Chin. J. Cancer 29: 38-42.

Satoh A, Toyota M, Itoh F, Kikuchi T, et al. (2002). DNA methylation and histone deacetylation associated with silencing DAP kinase gene expression in colorectal and gastric cancers. Br. J. Cancer 86: 1817-1823.

Topaloglu O, Hoque MO, Tokumaru Y, Lee J, et al. (2004). Detection of promoter hypermethylation of multiple genes in the tumor and bronchoalveolar lavage of patients with lung cancer. Clin. Cancer Res. 10: 2284-2288.

Toyooka S1, Toyooka KO, Maruyama R, Virmani AK, et al. (2001). DNA methylation profiles of lung tumors. Am. Assoc. Cancer Res. 1: 61-67.

Toyota M, Ahuja N, Ohe-Toyota M, Herman JG, et al. (1999). CpG island methylator phenotype in colorectal cancer. Proc Natl. Acad. Sci. U. S. A. 96: 8681-8686.

Vaissière T, Hung RJ, Zaridze D, Moukeria A, et al. (2009). Quantitative analysis of DNA methylation profiles in lung cancer identifies aberrant DNA methylation of specific genes and its association with gender and cancer risk factors. Cancer Res. 69: 243-252.

Wang L, Zhang F, Wu PP, Jiang XC, et al. (2006). Disordered beta-catenin expression and E-cadherin/CDH1 promoter methylation in gastric carcinoma. World J. Gastroenterol. 12: 4228-4231.

Wheeler JM, Kim HC, Efstathiou JA, Ilyas M, et al. (2001). Hypermethylation of the promoter region of the E-cadherin gene (CDH1) in sporadic and ulcerative colitis associated colorectal cancer. Gut 48: 367-371. 